\title{
PROGRESS ON BN AND DOPED-BN COATINGS ON WOVEN FABRICS
}

Frances I. Hurwitz

NASA Glenn Research Center

Cleveland, $\mathrm{OH} 44135$

John M. Scott

Refractory Composites, Inc.

Glen Burnie, MD 20160
Paul V. Chayka

ATMI, Inc.

Danbury, CT 06810

\begin{abstract}
A novel, multistep process for applying interface coatings to woven structures using a pulsed CVD process is being evaluated. Borazine $\left(\mathrm{B}_{3} \mathrm{~N}_{3} \mathrm{H}_{6}\right)$, a neat liquid, and several $\mathrm{Si}$ precursors are used in the process to produce $\mathrm{BN}$ and $\mathrm{SiBN}$ coatings on Hi- Nicalon fabrics and preforms. A three variable, two level, full factorial matrix is proposed to define the influence of processing parameters. Coating morphology, uniformity and chemistry are characterized by field emission scanning electron microscopy (FESEM), energy dispersive (EDS) and Auger spectroscopies.
\end{abstract}

\section{INTRODUCTION}

Boron nitride has been shown to provide a mechanically weak interphase in non-oxide ceramic matrix composites (CMCs), to yield tough composite behavior. $\mathrm{BN}$, however, is susceptible to oxidation from environmental oxygen and moisture, ${ }^{1-3}$ particularly at intermediate temperatures $\left(600-1000^{\circ} \mathrm{C}\right),{ }^{4,5}$ limiting material lifetimes. Such exposure of the interphase can occur either by oxygen diffusion along the interphase from exposed fiber ends, or through matrix cracks.

Susceptibility of BN to oxidation and moisture has been shown to be a function of BN morphology. High temperature deposited, turbostratic $\mathrm{BN}$ is more resistant to oxidation than are less crystalline, lower temperature coatings.

Oxygen diffusion is high in $\mathrm{B}_{2} \mathrm{O}_{3}$, the liquid reaction product of $\mathrm{BN}$ oxidation, but is much lower in $\mathrm{SiO}_{2}$. Therefore, doping of the $\mathrm{BN}$ interphase with $\mathrm{Si}$, which has a higher affinity for oxygen than $\mathrm{B}$, should provide a "gettering" effect, to form a high viscosity glass through which further oxygen ingress is substantially slowed, and which in effect acts as a sealant. ${ }^{6}$ Si-doped fiber coatings with good debonding characteristics have been demonstrated by Moore, Morscher and coworkers. ${ }^{7.8}$ These doped coatings, deposited at $1400^{\circ} \mathrm{C}$, were characterized as "glassy", and, when exposed to water vapor, showed

This report is a preprint of an article submitted to a journal for publication. Because of changes that may be made before formal publication, this preprint is made available with the understanding that it will not be cited or reproduced without the permission of the
author. 
resistance to recession along the interphase equal to that of a higher temperature $\left(1800^{\circ} \mathrm{C}\right.$ deposited pyrolytic $\mathrm{BN}$ ), and substantially greater than that of a low temperature deposited, undoped $B N$.

Improved moisture resistance relative to $\mathrm{BN}$ also has been demonstrated for SiBN ternary films deposited at low temperatures $\left(300-500^{\circ} \mathrm{C}\right) .^{9.10}$ This work has been focused in the electronics industry, rather than applied to structural composites.

Current commercially produced interphase coatings for structural composites are available for infiltration into 3D preforms. These coatings achieve very low levels of silicon dopant (3-5 atomic percent). Higher levels have been attained for deposition on cloth, but have failed to provide uniform coatings in preforms. The present work focuses on the development of a CVD reactor suitable for pulsed flow infiltration of 3D preforms, although the initial establishment of coating parameters will be carried out using $2 \mathrm{D}$ satin weave Hi-Nicalon ${ }^{\mathrm{TM}}$ cloth.

\section{COATING DEPOSITION}

Borazine $\left(\mathrm{B}_{3} \mathrm{~N}_{3} \mathrm{H}_{6}\right.$, b.p. $55^{\circ} \mathrm{C}$ ), a neat liquid with a high ( $40 \mathrm{wt} . \%$ ) boron yield, was used as the BN precursor. ${ }^{1-13}$ The precursor was synthesized by Boron Biologicals (Fancy Gap, VA), using a process patented by the Sneddon and Wideman. ${ }^{14,15}$ A refrigerated liquid delivery system developed by ATMI, Inc., (Danbury, CT) was used to introduce the borazine to the CVD reactor. Dichlorosilane served as the Si source.

A new batch process reactor was developed which utilizes a pulsed flow technique. Initial deposition runs to establish coating parameters are being carried out using 2D 5HS cloth woven at 17 ends per inch $\left(276 \mathrm{~g} / \mathrm{m}^{2}\right)$.

The pulsed flow process is essentially isothermal, and is expected to provide good infiltration of preforms. ${ }^{16,17}$ A series of specific steps, including variation in the gaseous species present in the reactor and the timing and duration of each processing step, control deposition rate and coating quality. The reactor design allows for overcoating the BN with $\mathrm{SiC}$ to protect the coating from moisture pick-up subsequent to $\mathrm{BN}$ coating deposition. Initial runs produced deposition rates of $200 \mathrm{~nm} / \mathrm{h}$. The system design is expected to provide improved infiltration of preforms so that any coating thickness gradient is minimized. It offers the potential to eliminate gas phase nucleation, to enable lower deposition temperatures, and to permit admixture of the dopant on a molecular level.

The precursor is maintained in a refrigerated reservoir at $-10^{\circ} \mathrm{C}$ to improve the stability of borazine. Multiple precursors can be used during a single run. The system has the capability to introduce four process and dopant gases in any desired sequence at specified rates, using a power and computer control system designed by Refractory Composites, Inc. (Glen Burnie, MD). 
The reactor has a working zone diameter of $20 \mathrm{~cm}$, and a length which can be varied from $30-60 \mathrm{~cm}$. for more efficient use of the precursor. Operating pressures are from 10 to several hundred torr. Maximum temperature capability is $1400^{\circ} \mathrm{C}$. The delivery system and reactor are shown in Figure 1.
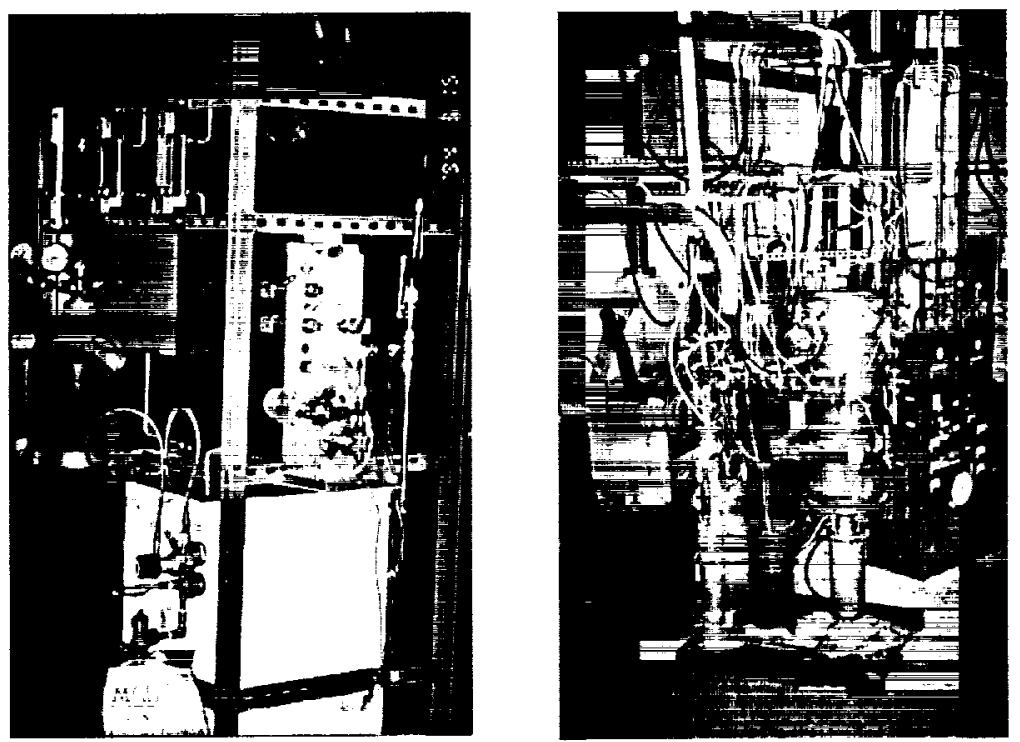

Figure 1. Precursor delivery system (left) and CVD reactor.

Possible processing variables include precursor delivery rate $(\mathrm{ml} / \mathrm{sec})$, duration of borazine delivery (sec), deposition temperature, reactor pressure, $\mathrm{H}_{2}$ and $\mathrm{NH}_{3}$ input timing, number of cycles and annealing temperature. To simplify an initial screening of parameters, a two level, three parameter, full factorial design was selected, in which the variables were pressure, temperature and number of cycles, as shown in Table I. All other processing variables were fixed, including the level of silicon dopant, which was targeted at 15 atomic percent $\mathrm{Si}$ relative to $\mathrm{B}$. All samples were heat treated for one hour at $1000^{\circ} \mathrm{C}$ following coating deposition, so as to encourage stabilization of the $\mathrm{BN}$ or SiBN.

Table I. Initial test matrix.

\begin{tabular}{|l|l|l|l|l|l|l|c|}
\hline $\begin{array}{l}\text { Exp. } \\
\text { No. }\end{array}$ & $\begin{array}{l}\text { Reactor P. } \\
\text { (torr) }\end{array}$ & $\begin{array}{l}\text { Reactor } \\
\text { temp. (C) }\end{array}$ & $\begin{array}{l}\text { Interact } \\
(\mathrm{AxB})\end{array}$ & $\begin{array}{l}\text { No. Cycles } \\
\text { temp. (C) }\end{array}$ & $\begin{array}{l}\text { Interact } \\
(\mathrm{AxC})\end{array}$ & $\begin{array}{l}\text { Interact } \\
(\mathrm{B} \times \mathrm{C})\end{array}$ & $\begin{array}{l}\text { Interact } \\
(\mathrm{AxB} \mathrm{B})\end{array}$ \\
\hline 1 & $1(50)$ & $1(350)$ & 1 & $1(50)$ & 1 & 1 & 1 \\
\hline 2 & $1(50)$ & $1(350)$ & 1 & $2(100)$ & 2 & 2 & 2 \\
\hline 3 & $1(50)$ & $2(600)$ & 2 & $1(50)$ & 1 & 2 & 2 \\
\hline 4 & $1(50)$ & $2(600)$ & 2 & $2(100)$ & 2 & 1 & 1 \\
\hline 5 & $2(100)$ & $1(350)$ & 2 & $1(50)$ & 2 & 1 & 2 \\
\hline 6 & $2(100)$ & $1(350)$ & 2 & $2(100)$ & 1 & 2 & 1 \\
\hline 7 & $2(100)$ & $2(600)$ & 1 & $1(50)$ & 2 & 2 & 1 \\
\hline 8 & $2(100)$ & $2(600)$ & 1 & $2(100)$ & 1 & 1 & 2 \\
\hline
\end{tabular}




\section{RESULTS AND DISCUSSION}

Initial FESEM and EDS characterization of the coated fabric samples revealed a wide variety of microstructures. EDS and initial Auger profiles also indicated the incorporation of substantial levels of oxygen in the BN coating. Such internal sources of oxygen can lead to the formation of a "layered" interphase structure, with formation of $\mathrm{SiO}_{2}$ and $\mathrm{Si}_{\mathrm{x}} \mathrm{BN}_{\mathrm{y}} \mathrm{O}_{\mathrm{z}}$ on further exposure to elevated temperatures. ${ }^{18,19}$ Internal formation of oxides have been shown to limit composite lifetimes. ${ }^{19}$ Several leaks were found in the system, and a number eliminated. However, oxygen incorporation in the coatings has continued to be a problem.

Early runs produced stiff fabrics and embrittled fibers, which broke upon handling the cloth. After elimination of the apparent leaks, coated fabrics were produced that were flexible and there was no evidence of fiber damage, although oxygen incorporation has persisted.

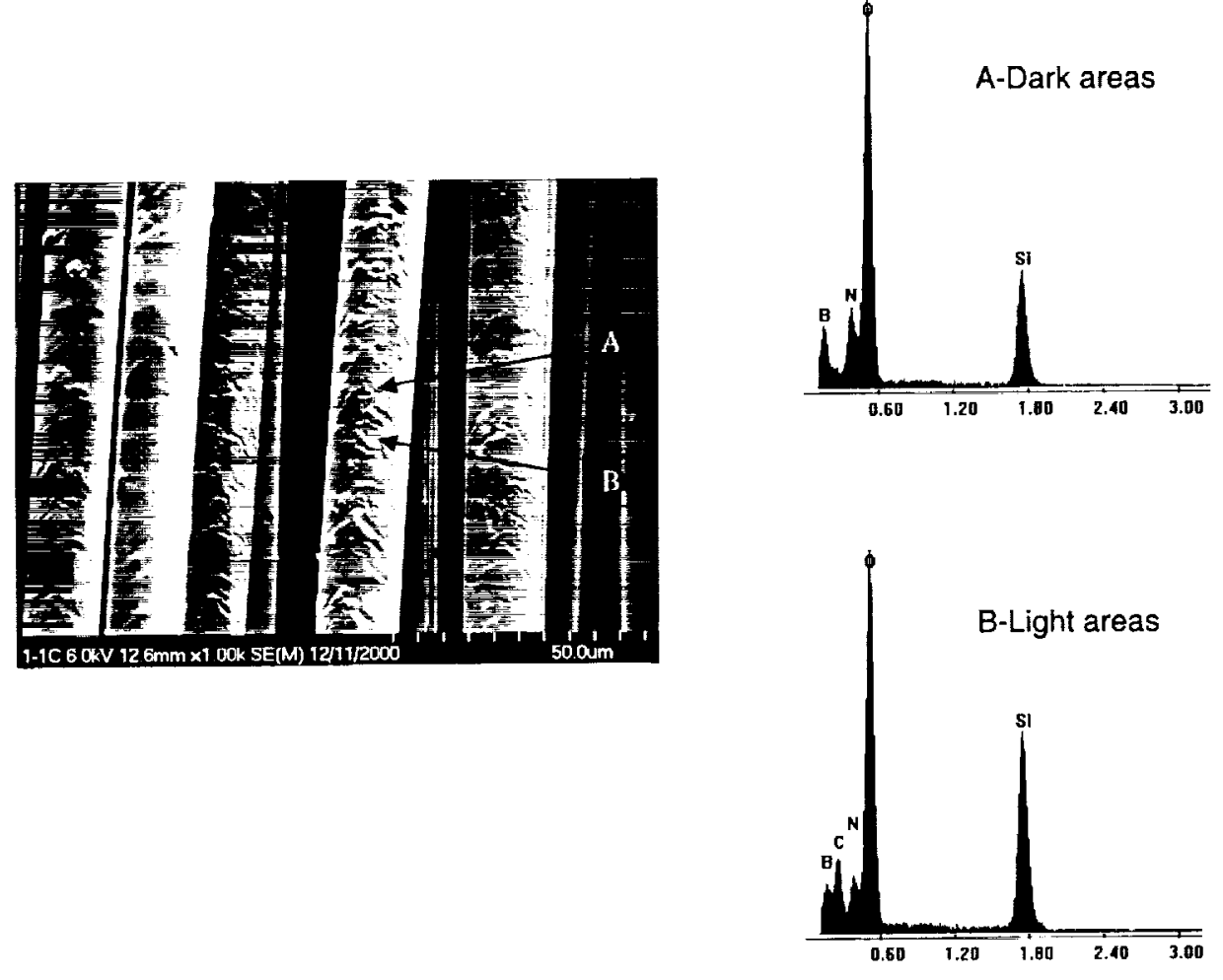

Figure 2. SiBN coating deposited at 50 torr, $350^{\circ} \mathrm{C}, 50$ cycles. 


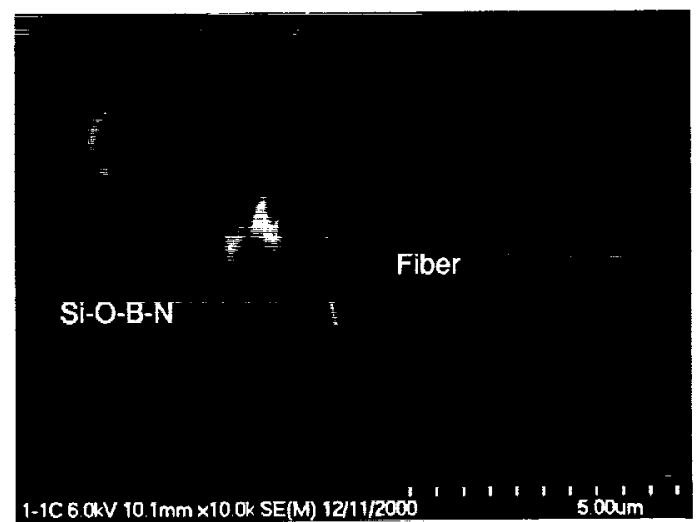

Figure 3. End-on view of fractured fiber from the same coating run shown in Figure 2. Note lighter contrast regions are recessed relative to darker areas. Coating thickness is nominally $0.5 \mu \mathrm{m}$.

One of the coating morphologies produced at 50 torr, $350^{\circ} \mathrm{C}, 50$ cycles (experimental condition 1), is shown in Figures 2 and 3. The coating in the dark areas, as indicated by point $\mathrm{A}$, Figure 2 , is nominally $0.5 \mu \mathrm{m}$ in thickness, as seen in end on views of the coated fiber (Figure 3). The coating appears to have shrunken and/or cracked, with light areas, indicated by point $B$, forming a type of "crazing" pattern. The end-on view also shows the light areas to be recessed relative to the darker regions.

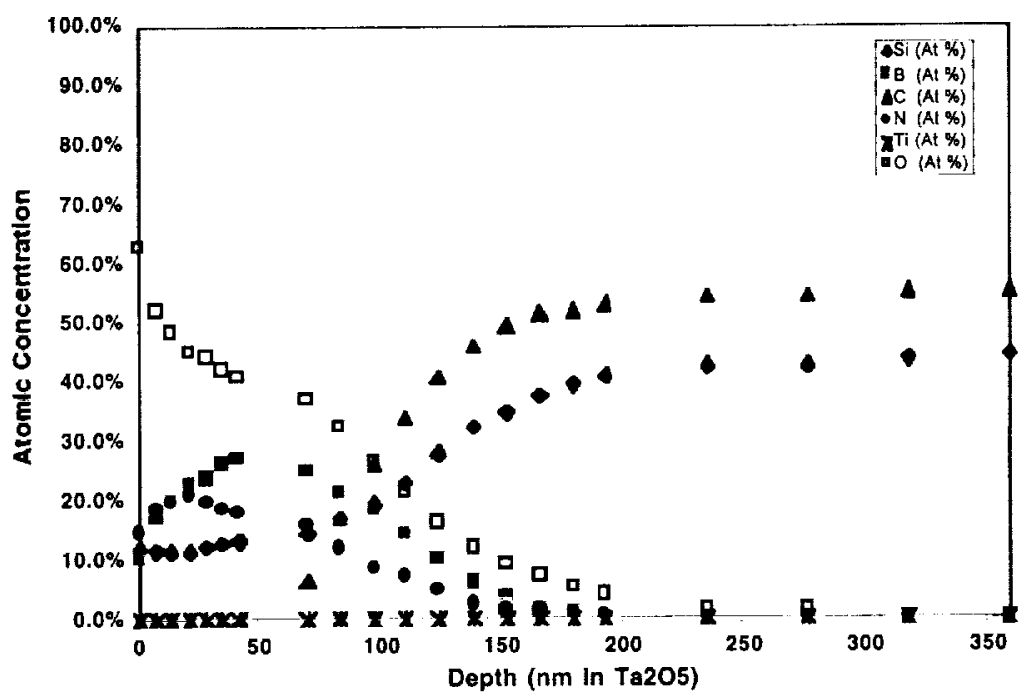

Figure 4. Auger spectra of coating in Figure 2, darker region.

The darker regions of the coating (A) contain B, N, a large O peak, and Si by EDS; the lighter, more glassy areas contain B, N, a large O peak, $\mathrm{Si}$ and some C. Auger spectra of the darker regions (Fig. 4) is consistent with the EDS findings, showing substantial 
oxygen incorporation in the coating, and a Si dopant level of nominally 11-13 atomic percent. (There is a shift in the Si peak for Si bonded to O vs. Si bonded to C.) The B/N ratio is 1 near the surface, but then becomes $\mathrm{N}$ deficient. There is no clear boundary

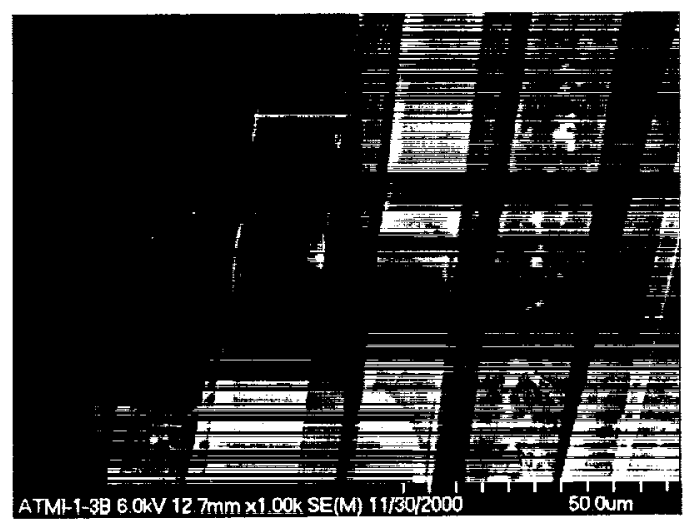

Figure 5. Coating deposited at $600^{\circ} \mathrm{C}$, experiment 3 .

between the coating and the fiber. Auger of the lighter region (not shown) indicates $\mathrm{C}$ incorporation just below the coating surface. Coatings deposited at $600^{\circ} \mathrm{C}$ (experimental condition 3, Table I) showed similar levels of Si incorporation, and some fibers showed similar coating shrinkage (Figure 5).

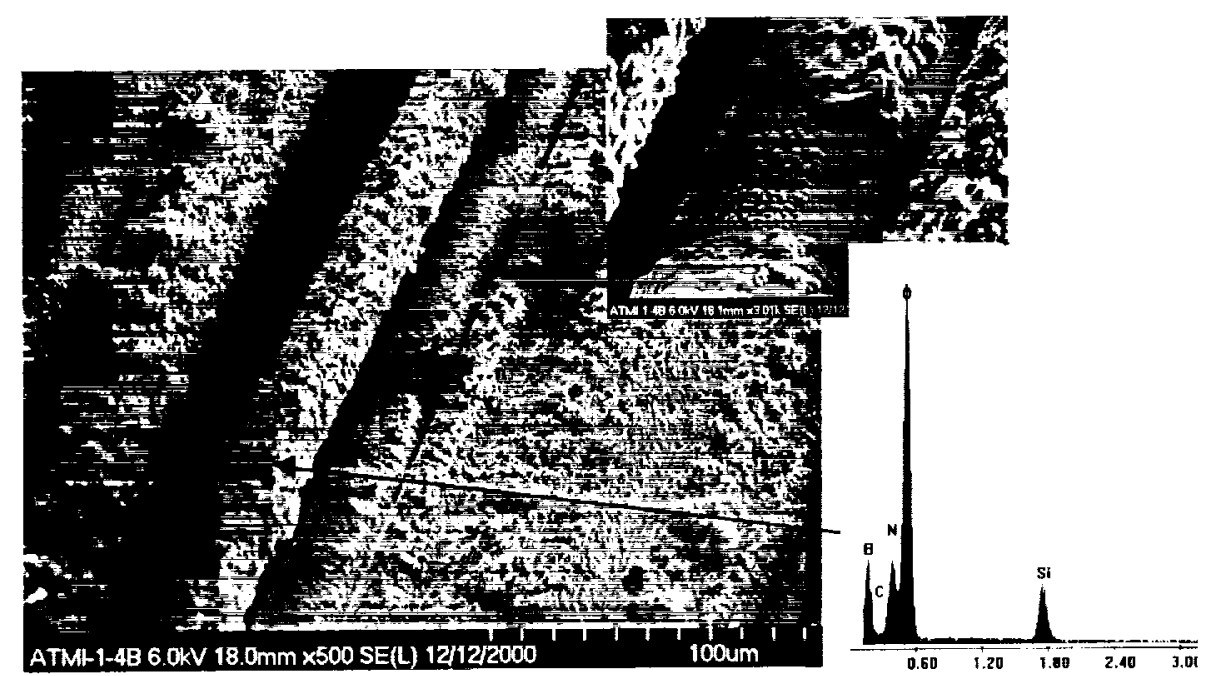

Figure 6. Coating deposited at $600^{\circ} \mathrm{C}, 100$ cycles.

A deposition run under experimental condition $4\left(600^{\circ} \mathrm{C}, 100\right.$ cycles) produced rougher, thicker coatings $(1.5-2.0 \mu \mathrm{m})$, with periodic gaps, and "bubbles" of Si-O-C on the fiber 
surface between those gaps (Figure 6). Substantial oxygen incorporation in the coating is noted by EDS.

Because of the high levels of oxygen incorporation in all the coatings, and a the large variation in coating morphology, a decision was made not to continue with the deposition experiments at higher reactor pressure until the oxygen incorporation could be eliminated. The source of oxygen incorporation has since been identified as impurities in several of the processing gases. Higher purity gases will be used for all subsequent runs.

\section{SUMMARY AND CONCLUSIONS}

A pulsed CVD coating reactor which includes a liquid delivery system with low temperature reservoir, a computer controlled gas manifold able to handle four process gases, and a variable volume reaction chamber has been designed and built to produce $\mathrm{BN}$ and Si doped BN coatings utilizing a borazine liquid precursor. Coating deposition has been demonstrated on cloth, with Si dopant levels on the order of 10-13 atomic percent. Deposition of the doped BN coatings has been accomplished at 350 and $600^{\circ} \mathrm{C}$, with $0.5 \mu \mathrm{m}$ coatings attained at 50 pulsed cycles at 50 torr. In several samples, coating uniformity within tows has been very promising.

All of the coatings contained unacceptably high levels of oxygen. Several leaks have been eliminated from the system, and gettering of process gases and substitution of higher purity gases is underway. Many of the coatings exhibited possible "crazing" or shrinkage cracks after heat treatment for one hour at $1000^{\circ} \mathrm{C}$ in the same reactor. This may be resolved with elimination of oxygen, or might require deposition at higher temperatures. (The system is capable of operating at temperatures to $1400^{\circ} \mathrm{C}$.)

Once the oxygen contamination is eliminated, the originally proposed test matrix will be repeated, initially without $\mathrm{Si}$ addition, to characterize a baseline BN coating. Following that, $\mathrm{Si}$ dopant level will be varied. Once uniform coatings are attained on $5 \mathrm{HS}$ cloth, infiltration of $3 \mathrm{D}$ preforms will be carried out, and these coatings characterized.

\section{ACKNOWLEDGMENTS}

The authors wish to than Terry R. McCue of Dynacs Engineering for field emission scanning electron microscopy and energy dispersive spectroscopy, and Dr. Donald R. Wheeler of NASA Glenn Research Center for Auger spectroscopy.

\section{REFERENCES}

1 N. Jacobson, S. Farmer, A. Moore, H. Sayir, "High-Temperature Oxidation of Boron Nitride: I, Monolithic Boron Nitride," J. Am. Ceram. Soc. 82, 393-98 (1999).

2 N. S. Jacobson, G. N. Morscher, D. R. Bryant, R. E. Tressler, "High-temperature Oxidation of Boron Nitride: II, Boron Nitride Layers in Composites," J. Am. Ceram. Soc. 82, 1473-82 (1999).

${ }^{3}$ K. L. More, P. F. Tortorelli, H. T. Lin, E. Lara-Curzio, R. A. Lowden, "Degradation Mechanisms of BN Interfaces in SiC/SiC Composites in Oxygen- and Water-Containing Environments," Proc. Electrochem. Soc. 98-9, 382-92 (1998). 
${ }^{4}$ G. N. Morscher, J. Hurst, D. Brewer, "Intermediate-Temperature Stress Rupture of a Woven Hi-Nicalon, BN-Interphase, SiC-Matrix Composite in Air," J. Am. Ceram. Soc. 83, 1441-1449 (2000).

${ }^{5}$ E. Y. Sun, H.-T. Lin, J. J. Brennan, "Intermediate-Temperature Environmental Effects on Boron Nitride-Coated Silicon Carbide-Fiber-Reinforced Glass-Ceramic Composites," J. Am. Ceram Soc. 80, 609-14 (1997).

${ }^{6}$ K. L. Luthra, "Oxidation-Resistant Fiber Coatings for Non-Oxide Ceramic Composites," J. Am. Ceram. Soc. 80, 3253-57 (1997).

${ }^{7}$ A. W. Moore, H. Sayir, S. C. Farmer, G. N. Morsher, "Improved Interface Coatings for SiC Fibers in Ceramic Composites," Ceram. Eng. Sci. Proc. 16, 409-416 (1995).

${ }^{8}$ G. N. Morscher, D. R. Bryant, R. E. Tressler, "Environmental Durability of BN-Based Interphases (for $\mathrm{SiCf} / \mathrm{SiCm}$ Composites) in $\mathrm{H} 2 \mathrm{O}$ Containing Atmospheres at Intermediate Temperatures," Ceram. Eng. Sci. Proc. 18, 525-34 (1997).

9 A. R. Phani, S. Roy, V. J. Rao, "Growth of Boron Nitride Thin Films by Metal-Organic Chemical Vapour Deposition," Thin Solid Films 258, 21-25 (1995).

${ }^{10}$ M. Maeda, T. Makino, "Low Dielectric Constant Amorphous SiBN Ternary Films Prepared by Plasma-Enhanced Deposition," Jap. J. Appl. Phys. 26, 660-665 (1987).

"I J. Kouvetakis, V. V. Patel, C. W. Miller, D. B. Beach, "Composition and Structure of Boron Nitride Films Deposited by Chemical Vapor Deposition from Borazine," J. Vac. Sci. Technol. A 8, 3929-3933 (1990).

${ }_{12}$ W. F. Kane, S. A. Cohen, J. P. Hummel, B. Luther, D. B. Beach, "Use of SiBN and SiBON Films Prepared by Plasma Enhanced CVD from Borazine as Interconnection Dielectrics," $J$. Electrochem. Soc. 144, 658-663 (1997).

${ }^{13}$ B. A. Bender, R. W. Rice, J. R. Spann, "Evaluation of Potential BN Precursors," Ceram. Eng. Sci. Proc. 6, 1171-83 (1985).

${ }_{14}$ L. G. Sneddon, T. Wideman, "Method for Synthesis of Borazine", US Patent 5,612,013, March 18, 1997.

${ }^{15}$ T. Wideman, L. G. Sneddon, "Convenient Procedures for the Laboratory Preparation of Borazine," Inorganic Chemistry 34, 1002-3 (1995).

${ }^{16}$ V. Cholent, L. Vandenbulcke, "Chemical Vapor Infiltration of Boron Nitride Interphase in Ceramic Fiber Preforms: Discussion of Some Aspects of the Fundamentals of the Isothermal Chemical Vapor Infiltration Process," J. Am. Ceram. Soc. 76, 2846-58 (1993).

${ }^{17}$ M. Leparoux, et al., "Oxidizing Environment Influence on the Mechanical Properties and Microstructure of 2D-SiC/BN/SiC Composites Processed by CVI," J. European Ceram. Soc. 18, 715-23 (1998).

${ }_{18}$ F. I. Hurwitz, et al., "BN and SiBN Fiber Coatings via CVD using a Single Source, Liquid Precursor Based on Borazine," Ceram. Eng. Sci. Proc. 21, 267-274 (2000).

${ }^{19}$ K. L. More, K. S. Ailey, R. A. Lowden, H. T. Lin, "Evaluating the Effect of Oxygen Content in BN Interfacial Coatings on the Stability of SiC/BN/SiC Composites," Composites Part A: Appl. Sci. and Manufacturing 30, 463-470 (1999). 